\title{
Effect of PPAR- $\gamma$ Agonist Treatment on Markers of Endothelial Dysfunction in Patients with Type 2 Diabetes Mellitus
}

R. DOLEŽALOVÁ ${ }^{1}$, M. M. HALUZÍK ${ }^{1,2}$, L. BOŠANSKÁ ${ }^{1}$, Z. LACINOVÁ $^{1}$, Z. KASALOVÁ ${ }^{1}$, T. ŠTULC ${ }^{1}$, M. HALUZÍIK ${ }^{1}$

${ }^{1}$ Third Department of Medicine, First Faculty of Medicine, Charles University, Prague and

${ }^{2}$ Department of Chemistry, Faculty of Science, University of Ostrava, Ostrava, Czech Republic

Received July 3, 2006

Accepted October 18, 2006

On-line available November 6, 2006

\begin{abstract}
Summary
Thiazolidinediones are insulin-sensitizing drugs acting through peroxisome proliferator-activated receptor (PPAR)- $\gamma$. The aim of our study was to evaluate the effect of 5-month treatment with PPAR- $\gamma$ agonist - rosiglitazone (4 mg/day), on the circulating markers of endothelial dysfunction and to evaluate the role of changes in endocrine function of adipose tissue in this process. Biochemical and metabolic parameters, circulating adiponectin, resistin, ICAM-1, VCAM-1, E-selectin, P-selectin, PAI-1, myeloperoxidase (MPO), and matrix metalloproteinase-9 (MMP-9) concentrations were assessed in 10 women with type $2 \mathrm{DM}$ before and after rosiglitazone treatment and in a control group of healthy women. At baseline, diabetic group had significantly higher serum concentrations of glucose, glycated hemoglobin, V-CAM and PAI-1 compared to control group. Adiponectin levels tended to be lower in diabetic group, while resistin concentrations did not differ from control group. Rosiglitazone treatment improved diabetes compensation, significantly reduced VCAM-1, PAI-1 and E-selectin concentrations and increased adiponectin levels, while it did not affect serum resistin concentrations. Adiponectin concentrations at baseline were inversely related to E-selectin and MPO levels, this correlation disappeared after rosiglitazone treatment. We conclude that 5-month rosiglitazone treatment significantly reduced several markers of endothelial dysfunction. This effect could be at least in part attributable to marked increase of circulating adiponectin levels.
\end{abstract}

\section{Key words}

Diabetes mellitus $\bullet$ Endothelial dysfunction $\bullet$ Thiazolidinediones $\bullet$ Cardiovascular risk $\bullet$ Adipocyte-derived hormones

\section{Introduction}

Combination of visceral obesity, insulin resistance/diabetes, arterial hypertension, dyslipidemia and numerous other pathological states is now referred to as the metabolic or Reaven syndrome (Reaven 1988).
Many epidemiological studies have demonstrated that presence of this syndrome markedly increases the risk of cardiovascular morbidity and mortality (Haffner 2003a,b, Haffner et al. 1998). Although the connection between the metabolic syndrome and cardiovascular complications is firmly established, the underlying pathophysiological 
mechanisms are only partially understood. One of the possible links between the metabolic syndrome and enhanced atherogenesis include a metabolic and endocrine dysfunction of adipose tissue with increased release of free fatty acids, enhanced production of insulin resistance-inducing and decreased production of insulinsensitizing adipose tissue-derived hormones (Ravussin and Smith 2002, Haluzík et al. 2004, Haluzík and Haluzíková 2006). Therefore, one of the possible therapeutic approaches to prevent the development of atherosclerosis in patients with the metabolic syndrome is to improve metabolic and endocrine dysfunction of the adipose tissue.

One of the few drug classes with clearly established favorable effects on impaired endocrine function of the adipose tissue are thiazolidinediones (TZDs) (Olefsky 2000, Combs et al. 2002). These substances exert their effects by stimulating of peroxisome proliferators-activated receptors (PPAR)- $\gamma$ that are most abundantly expressed in adipose tissue (Vamecq and Latruffe 1999). Peroxisome proliferatoractivated receptors (PPARs) are nuclear transcription factors that regulate gene expression in response to activation by specific ligands (Fruchart et al. 2002, Haluzík and Haluzík 2006). PPARs are highly expressed in several tissues, including the adipose tissue, monocytes/macrophages and smooth muscle cells (Loviscach et al. 2000). Both experimental and clinical data clearly show that stimulation of PPAR- $\gamma$ receptor by exogenous ligands such as thiazolidinediones improve insulin sensitivity, diabetes compensation and in some studies also blunt the atherogenic processes (Nolan et al. 1994, Saltiel and Olefsky 1996, Blaschke et al. 2006). Rosiglitazone - one of the powerful synthetic PPAR- $\gamma$ agonists - is now widely used in the treatment of type 2 diabetes (Mayerson et al. 2002). Numerous studies also documented a positive effect of thiazolidinediones on circulating lipid levels namely decrease of triglycerides and fatty acids concentrations, and increase of HDLcholesterol (Tan et al. 2005). Furthermore, TZDs exhibit many additional properties such as an important antiinflammatory action and anti-atherogenic effects.

Here we tested the effect of chronic rosiglitazone treatment on selected metabolic and hormonal parameters in patients with type 2 diabetes mellitus. We hypothesized that activation of PPAR- $\gamma$ receptors not only improves insulin sensitivity but also exerts antiatherogenic effects in patients with type 2 diabetes. Furthermore, we tested the hypothesis that this effect may in addition improve diabetes compensation mediated by changes of endocrine function of adipose tissue. To this end, we measured circulating markers of endothelial dysfunction and atherosclerosis in patients with type 2 diabetes before and after treatment with PPAR- $\gamma$ agonist rosiglitazone and correlated these parameters with circulating levels of adipose tissue-derived hormones adiponectin and resistin.

\section{Patients and Methods}

\section{Study subjects}

Ten female subjects with type 2 diabetes mellitus (DM duration $6.3 \pm 1.8$ years) and ten sexmatched healthy controls were included in the study. The group of patients with type $2 \mathrm{DM}$ had been treated with peroral antidiabetic drugs (metformine) in monotherapy for at least 6 months before the beginning of the study. Four patients with type $2 \mathrm{DM}$ were treated with statins and another four of them with fibrates for at least 6 months before beginning of the study. Body weight of the subjects remained stable for at least three months before enrolment in the study. None of the studied subjects suffered from any acute infectious disease. Written informed consent was provided by all participants before being enrolled in the study. The study was approved by the Human Ethical Review Committee, First Faculty of Medicine and General University Hospital, Prague, Czech Republic.

\section{Study protocol}

Subjects were treated with rosiglitazone in a dose $4 \mathrm{mg} /$ day for 5 months (148 \pm 5.3 days). All patients were examined in the basal state before the start of rosiglitazone administration and after 5 months of rosiglitazone treatment. Control subjects underwent only one physical examination and blood withdrawal and received no medication. All subjects were measured and weighed. Blood samples were withdrawn between 7:00 and 8:00 $\mathrm{h}$ after overnight fasting.

\section{Hormonal and biochemical assays}

Serum concentrations of soluble E-selectin (sESelectin), soluble VCAM-1 (sVCAM-1), soluble ICAM1 (sICAM-1), matrix metalloproteinase-9 (MMP-9), myeloperoxidase (MPO), and total plasminogen activator inhibitor-1 (PAI-1) were measured by multiplex assay LINCOplex Kits (Linco Research, St. Charles, Missouri, USA). Sensitivity for analytes were sE-Selectin $79 \mathrm{pg} / \mathrm{ml}$, 
Table 1. Anthropometric and biochemical parameters of control group of healthy women and subjects with type 2 DM before (DM group 1) and after (DM group 2) five months of rosiglitazone administration.

\begin{tabular}{lccl}
\hline & $\begin{array}{c}\text { Control } \\
\text { group } \\
(\mathbf{n = 1 0})\end{array}$ & $\begin{array}{c}\text { DM } \\
\text { group 1 } \\
(\mathbf{n = 1 0})\end{array}$ & $\begin{array}{c}\text { DM } \\
\text { group 2 } \\
(\mathbf{n = 1 0})\end{array}$ \\
& $54.9 \pm 1.3$ & \multicolumn{2}{c}{$63.3 \pm 2.7^{*}$} \\
Age & $25 \pm 1.1$ & $29.9 \pm 1.2^{*}$ & $29.8 \pm 1.2^{*}$ \\
BMI $\left(\mathrm{kg} / \mathrm{m}^{2}\right)$ & $1.6 \pm 0.6$ & $3.7 \pm 1.2$ & $2.5 \pm 0.6$ \\
CRP $(\mathrm{mg} / \mathrm{l})$ & $4.7 \pm 0.3$ & $8.9 \pm 0.6^{* *}$ & $7.2 \pm 0.4^{* * \circ}$ \\
gly $(\mathrm{mmol} / \mathrm{l})$ & $4.0 \pm 0.1$ & $5.4 \pm 0.2^{* *}$ & $5.2 \pm 0.3^{*}$ \\
$\mathrm{HbAlc}(\%)$ & $1.1 \pm 0.1$ & $1.4 \pm 0.1$ & $1.4 \pm 0.1$ \\
TAG $(\mathrm{mmol} / \mathrm{l})$ & $5.6 \pm 0.2$ & $4.1 \pm 0.7^{* *}$ & $4.4 \pm 0.2^{* *}$ \\
Chol. $(\mathrm{mmol} / \mathrm{l})$ & $1.7 \pm 0.1$ & $1.2 \pm 0.1^{*}$ & $1.4 \pm 0.1$ \\
HDL $(\mathrm{mmol} / \mathrm{l})$ & $3.4 \pm 0.2$ & $2.2 \pm 0.2^{*}$ & $2.3 \pm 0.4^{* *}$ \\
LDL $(\mathrm{mmol} / \mathrm{l})$ & & & \\
\hline
\end{tabular}

Values are means \pm S.E.M. Statistical significance is from oneway ANOVA and Paired t-test respectively. $* \mathrm{p}<0.05$ vs. control group, ${ }^{* *} p<0.001$ vs. control group; ${ }^{\circ} p<0.05$ DM group 1 (before treatment) vs. DM group 2 (after treatment). BMI body mass index, HbA1c - glycated hemoglobin

sVCAM-1 16 pg/ml, sICAM-1 9 pg/ml, MMP-9 1 pg/ml, MPO $7 \mathrm{pg} / \mathrm{ml}$, tPAI-1 $1 \mathrm{pg} / \mathrm{ml}$. The intra- and interassay variability were 4.5-12.3 \% and 8.5-16.3\%, respectively. Serum adiponectin concentrations were measured by commercial ELISA kit (Linco Research, USA). Sensitivity was $1.0 \mathrm{ng} / \mathrm{ml}$, and the intra- and interassay variability were $1.78 \%$ and $9.25 \%$, respectively. Serum resistin concentrations were measured by commercial ELISA kit (BioVendor, Czech Republic). Sensitivity was $0.2 \mathrm{ng} / \mathrm{ml}$ and the intra- and interassay variability were $3.1 \%$ and $6.5 \%$, respectively. Plasma glucose and lipids levels were measured by standard laboratory methods in the Department of Biochemistry of the General University Hospital.

\section{Statistical analysis}

The statistical analysis was performed on SigmaStat software (Jandel Scientific, USA). The results are expressed as means \pm S.E.M. Data of diabetic patients before and after rosiglitazone treatment were compared by a paired t-test. Data of control subjects and of diabetic patients before and after rosiglitazone treatment respectively were compared by one-way analysis of variance followed by Dunn's test. Correlations between adipocyte-derived hormones and endothelial dysfunction markers levels were evaluated by Spearman's correlation test.
Adiponectin

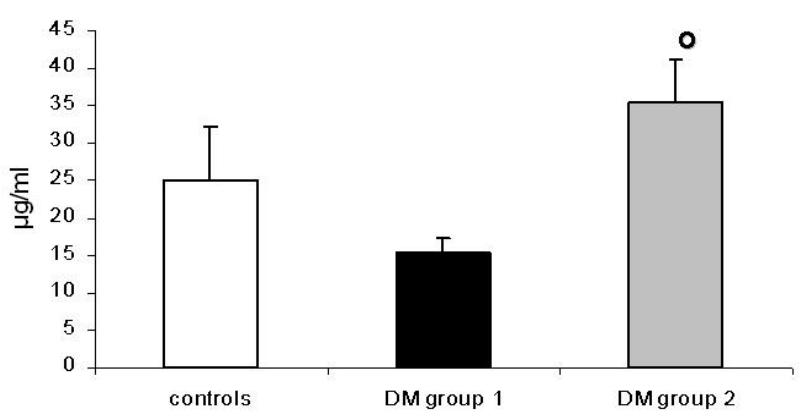

Fig. 1. Adiponectin concentrations in control group of healthy women and subjects with type 2 DM before (DM group 1) and after (DM group 2) five months of administration of rosiglitazone. Values are means \pm S.E.M. Statistical significance is from one-way ANOVA and paired t-test, respectively. $\circ p<0.05$ DM group 1 (before treatment) vs. DM group 2 (after treatment).

\section{Results}

Anthropometric values and parameters of diabetes compensation

At baseline, BMI in the DM2 group before treatment was significantly higher than in the control group. Rosiglitazone treatment did not significantly affect this variable (Table 1). Serum glucose and HbA1c concentrations in DM2 group were significantly higher than in the control group. Treatment with rosiglitazone significantly decreased glucose concentrations and tended to lower HbAlc concentrations (Table 1). Serum concentrations of total cholesterol, LDL-cholesterol and HDL-cholesterol in women with DM2 before treatment were significantly lower than in the control group (Table 1). Neither systolic or diastolic blood pressure values were significantly affected by rosiglitazone treatment (data not shown).

\section{Adipose tissue-derived hormones and parameters of endothelial dysfunction}

Baseline adiponectin concentration tended to be reduced in the diabetic group (15.5 \pm 1.9 vs. $25.2 \pm 7$, $\mathrm{p}=0.08$ ) while serum resistin concentrations were comparable between the groups. Rosiglitazone treatment significantly increased serum adiponectin levels (Fig. 1) but it did not affect serum resistin concentrations (Fig. 2).

At baseline, diabetic patients had higher total sVCAM-1 and PAI-1 concentrations relative to the control group (Table 2). There was a similar nonsignificant tendency for MMP-9, ICAM and E-selectin. MPO levels in the diabetic group were comparable to 


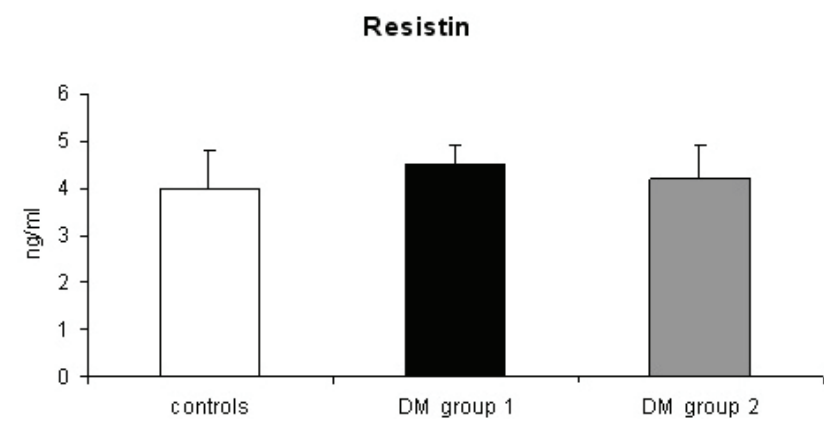

Fig. 2. Resistin concentrations in control group of healthy women and subjects with type 2 DM before (DM group 1) and after (DM group 2) five months of rosiglitazone administration. Values are means \pm S.E.M.

those of the control group (Table 2). Treatment with rosiglitazone significantly decreased sVCAM, PAI-1 and E-selectin concentrations, while it did not significantly affect serum concentrations of sICAM, MPO and MMP-9 (Table 2).

Relationship of circulating adiponectin and resistin levels to parameters of endothelial dysfunction

Adiponectin concentrations in diabetic group before rosiglitazone treatment negatively correlated with MPO ( $\mathrm{r}=-0.648, \mathrm{p}<0.05)$ and E-selectin $(\mathrm{r}=-0.709$, $\mathrm{p}<0.05)$ levels. Baseline resistin levels tended to correlate positively with MPO levels $(r=0.612, p=0.051)$. No significant correlations were found between adiponectin and resistin and other endothelial dysfunction markers levels before and after treatment.

\section{Discussion}

Obesity clusters with numerous abnormalities such as dyslipidemia, arterial hypertension or insulin resistance/diabetes and this combination is now commonly referred to as a metabolic or Reaven syndrome (Reaven 1988, 1992, 2001). The importance of this syndrome lies in the fact that its presence markedly increases the risk of atherosclerosis with subsequently enhanced cardiovascular morbidity and mortality (Haffner et al. 1996, Howard et al. 1998). Overt atherosclerotic changes of the vessel wall are usually preceded with its functional abnormalities such as increased rigidity, blunted response to vasodilatory agents and increased activation of endothelium (Esper et al. 2006). Increased endothelial activation is accompanied by enhanced production of endothelial molecules such as E-selectin, ICAM-1 and VCAM-1 that interact with other factors to promote atherogenesis (Huo and Ley 2001).
Table 2. Circulating markers of endothelial dysfunction in control subjects and subjects with type 2 DM before (DM group 1) and after (DM group 2) five months of rosiglitazone administration.

\begin{tabular}{lccc}
\hline & $\begin{array}{c}\text { Control } \\
\text { group } \\
(\mathbf{n}=\mathbf{1 0})\end{array}$ & $\begin{array}{c}\text { DM } \\
\text { group 1 } \\
(\mathbf{n = 1 0})\end{array}$ & $\begin{array}{c}\text { DM } \\
\text { group 2 } \\
(\mathbf{n = 1 0})\end{array}$ \\
\hline MMP-9 & $133 \pm 19.4$ & $193 \pm 24.8$ & $130 \pm 37.7$ \\
VCAM-1 & $1287.3 \pm 61$ & $1501.6 \pm 73.2^{*}$ & $1244.2 \pm 110.1^{\circ}$ \\
sICAM-1 & $164.9 \pm 35.5$ & $195.8 \pm 23.2$ & $176.2 \pm 17.8^{\circ}$ \\
PAI-1 & $28.6 \pm 2.1$ & $46.4 \pm 5.1^{*}$ & $36.6 \pm 3.9^{\circ}$ \\
MPO & $58.3 \pm 13.3$ & $62.1 \pm 19.3$ & $61.29 \pm 20.1$ \\
E-sel. & $18.2 \pm 2.4$ & $26.2 \pm 4.4$ & $21.0 \pm 3.3^{\circ}$ \\
\hline
\end{tabular}

Values are means \pm S.E.M. Statistical significance is from oneway ANOVA and paired t-test, respectively. ${ }^{*} p<0.05$ vs. control group, ${ }^{\circ} p<0.05$ DM group 1 (before treatment) vs. DM group 2 (after treatment). ICAM-1 - intercellular adhesion molecule 1, VCAM-1 - vascular cell adhesion molecule 1, MPO myeloperoxidase, MMP-9 - matrix metalloproteinase-9.

Due to the complex nature of interactions between components of the metabolic syndrome and atherosclerosis it is important to search for pharmacological approaches that can target several if not all components of metabolic syndrome at the same time.

PPAR- $\gamma$ agonists - thiazolidinediones represent one of the most promising candidates to fulfill the above mentioned requirements. They were originally discovered as insulin-sensitizing agents and used to treat diabetes and insulin resistance (Lehmann et al. 1995, Saltiel and Olefsky 1996). However, further studies have indicated that these drugs have a number of other beneficial effects beyond its insulin-sensitizing and blood glucose-lowering properties (Komers and Vrána 1998, Su et al. 1999, Moore et al. 2001). Here we have demonstrated that 5 months of treatment with potent PPAR- $\gamma$ agonist rosiglitazone not only improved diabetes compensation but also decreased circulating levels of VCAM, PAI-1 and E-selectin, thus indicating improvement of endothelial dysfunction. It also tended to decrease circulating levels of matrix metalloproteinase- 9 which has a proteolytic activity against connective tissue proteins and is involved in atherogenesis, vascular remodeling, and the creation and rupture of atherosclerotic plaques (Dandona et al. 2003). Although the baseline differences in circulating endothelial molecules between diabetic and control group could have been slightly affected by lower age of the latter group, our data (albeit on a relatively small number of patients) 
show a clear improvement of endothelial dysfunction markers after rosiglitazone treatment in patients with type 2 diabetes. This finding is in agreement with previously published studies showing that thiazolidinediones improve the mechanic properties of the vessel wall (Caballero et al. 2003, Esposito et al. 2006), although it has to be noted that not all of the clinical studies supported this concept (Buras et al. 2005).

There are several possible explanations of the beneficial effects of rosiglitazone treatment on endothelial dysfunction in our study. Firstly, chronically increased blood glucose levels as seen in patients with diabetes have numerous negative metabolic effects including a direct proatherogenic action through a multiple mechanism (Ceriello 2005, Lim et al. 2006). Therefore the improvement of diabetes compensation could have affected endothelial activation by itself. Another unifying hypothesis between obesity, insulin resistance and atherosclerosis concerns impaired endocrine function of adipose tissue with increased production of proinflammatory and insulin resistanceinducing factors and decreased production of insulinsensitizing hormones (Havel 2002). Here we have focused on the possible involvement of two adipose tissue-derived hormones that have been implicated in the etiopathogenesis of both insulin resistance and atherosclerosis. First one, adiponectin, is a protein hormone produced almost exclusively by adipocytes with important insulin-sensitizing properties (Berg et al. 2002). Furthermore, transgenic adiponectin-knockout mice also exhibit exaggerated atherosclerosis that is blunted by adiponectin replacement (Kubota et al. 2002). Clinical studies have shown that decreased adiponectin levels are linked to accelerated atherosclerosis (Shimada et al. 2004). Another adipose tissue-derived hormone studied herein, resistin, possesses properties that are in many respects opposite to those of adiponectin. It has been reported to be higher in rodent models of obesity and insulin resistance and it has been shown to promote atherogenesis (Steppan et al. 2001, Kawanami et al. 2004). Clinical studies have not fully supported its role as a link between obesity and insulin resistance but most of them linked increased resistin levels to increased risk of atherosclerosis (Kawanami et al. 2004, Anderlová et al. 2005, Pischon et al. 2005). Here we have shown in accordance with previously published studies that rosiglitazone administration markedly increased circulating adiponectin levels which in turn may have directly affected endothelial activation and possibly also circulating MMP-9 levels. It has been demonstrated previously that adiponectin levels are lower in patients with microalbuminuria relative to those without microalbuminuria indicating a relationship of this hormone to microalbuminuria as another measure of endothelial dysfunction (Tsioufis et al. 2005). Our data indicate that activation of PPAR- $\gamma$ receptors can target atherosclerosis at least in part through the stimulation of adiponectin production in adipose tissue. Furthermore, since PPAR- $\gamma$ receptors are also present in circulating monocytes and macrophages, it is possible that rosiglitazone can also directly affect this potential source of proatherogenic and proinflammatory factors.

In contrast to adiponectin levels clearly influenced by rosiglitazone treatment we did not observe any effect of PPAR- $\gamma$ activation on circulating resistin levels. This observation underlines relatively controversial findings regarding the importance of resistin in the etiopathogenesis of insulin resistance and atherosclerosis in humans. Firstly, resistin in humans appears (in contrast to rodents) to be produced predominantly, if not exclusively, by immunocompetent cells rather than by adipocytes (Savage et al. 2001). Secondly, while some studies showed increased circulating resistin levels in human obesity and type 2 diabetes, many others including our data failed to do so (McTernan et al. 2002, Anderlová et al. 2005). Finally, it has been shown that resistin secretion is strongly activated by endotoxin administration indicating that its major role in humans may lie rather in the regulation of inflammation than insulin sensitivity (Lehrke et al. 2004). Here we did not see any effect of rosiglitazone treatment on the circulating resistin levels despite a clear improvement of diabetes compensation and endothelial dysfunction, although we cannot exclude the possibility that resistin production was affected only locally in adipose tissue without major changes in systemic resistin concentrations. Taken together, our study does not support the role for resistin as a link between obesity, insulin resistance and atherosclerosis in humans.

In conclusion, we have demonstrated that treatment with PPAR- $\gamma$ agonist rosiglitazone for 5 months markedly improved diabetes compensation and circulating markers of endothelial dysfunction. The beneficial effect on endothelial dysfunction can very likely be explained by the combination of glucoselowering effect of rosiglitazone and by increased circulating levels of anti-atherogenic hormone adiponectin. The direct influence of PPAR- $\gamma$ activation 
combined with increased adiponectin levels probably affected the production of endothelial dysfunction markers in both the vasculature and adipose tissue that has been previously shown as a source of these molecules especially in subjects with obesity (Plomgaard et al. 2005). In contrast, resistin levels were not affected by rosiglitazone treatment in our study suggesting that this hormone in not involved in the improvement of insulin sensitivity and endothelial dysfunction after rosiglitazone treatment.

\section{Acknowledgements}

Supported by Research Project of MH CR No. 64165.

\section{References}

ANDERLOVÁ K, KŘEMEN J, DOLEŽALOVÁ R, HOUSOVÁ J, HALUZÍKOVÁ D, KUNEŠOVÁ M, HALUZÍK M: The influence of very-low-calorie-diet on serum leptin, soluble leptin receptor, adiponectin and resistin levels in obese women. Physiol Res, 55: 277-283, 2006.

BERG AH, COMBS TP, SCHERER PE: ACRP30/adiponectin: an adipokine regulating glucose and lipid metabolism. Trends Endocrinol Metab 13: 84-89, 2002.

BLASCHKE F, SPANHEIMER R, KHAN M, LAW RE: Vascular effects of TZDs: new implications. Vascul Pharmacol 45: 3-18, 2006.

BURAS J, REENSTRA WR, ORLOW D, HORTON ES, VEVES A: Troglitazone-induced changes in adiponectin do not affect endothelial function in diabetes. Obes Res 13: 1167-1174, 2005.

CABALlERO AE, SAOUAF R, LIM SC, HAMDY O, ABOU-ELENIN K, O'CONNOR C, LOGERFO FW, HORTON ES, VEVES A: The effects of troglitazone, an insulin-sensitizing agent, on the endothelial function in early and late type 2 diabetes: a placebo-controlled randomized clinical trial. Metabolism 52: 173-180, 2003.

CERIELLO A: Postprandial hyperglycemia and diabetes complications: is it time to treat? Diabetes 54: 1-7, 2005.

COMBS TP, WAGNER JA, BERGER J, DOEBBER T, WANG WJ, ZHANG BB, TANEN M, BERG AH, O'RAHILLY S, SAVAGE DB, CHATTERJEE K, WEISS S, LARSON PJ, GOTTESDIENER KM, GERTZ BJ, CHARRON MJ, SCHERER PE, MOLLER DE: Induction of adipocyte complement-related protein of 30 kilodaltons by PPARgamma agonists: a potential mechanism of insulin sensitization. Endocrinology 143: 9981007, 2002.

DANDONA P, ALJADA A, MOHANTY P, GHANIM H, BANDYOPADHYAY A, CHAUDHURI A: Insulin suppresses plasma concentration of vascular endothelial growth factor and matrix metalloproteinase-9. Diabetes Care 26: 3310-3314, 2003.

ESPER RJ, NORDABY RA, VILARINO JO, PARAGANO A, CACHARRON JL, MACHADO RA: Endothelial dysfunction: a comprehensive appraisal. Cardiovasc Diabetol 5: 4, 2006.

ESPOSITO K, CIOTOLA M, CARLEO D, SCHISANO B, SACCOMANNO F, SASSO FC, COZZOLINO D, ASSALONI R, MERANTE D, CERIELLO A, GIUGLIANO D: Effect of rosiglitazone on endothelial function and inflammatory markers in patients with the metabolic syndrome. Diabetes Care 29: 1071-1076, 2006.

FRUCHART JC, GOTTO AM, PAOLETTI R, STAELS B, CATAPANO AL: PPARs: From Basic Science to Clinical Applications, 2002. Kluwer Academic Publishers, New York, Rome, 2002.

HAFFNER SM: Insulin resistance, inflammation, and the prediabetic state. Am J Cardiol 92: 18J-26J, 2003a.

HAFFNER SM: Pre-diabetes, insulin resistance, inflammation and CVD risk. Diabetes Res Clin Pract 61 (Suppl 1): S9-S18, 2003b.

HAFFNER SM, LEHTO S, RONNEMAA T, PYORALA K, LAAKSO M: Mortality from coronary heart disease in subjects with type 2 diabetes and in nondiabetic subjects with and without prior myocardial infarction. $N$ Engl J Med 339: 229-234, 1998.

HALUZÍK M, HALUZÍKOVÁ D: The role of resistin in obesity-induced insulin resistance. Curr Opin Investig Drugs 7: 306-311, 2006.

HALUZÍK MM, HALUZÍK M: PPAR-alpha and insulin sensitivity. Physiol Res 55: 115-122, 2006.

HALUZÍK M, PAŘÍZKOVÁ J, HALUZÍK MM: Adiponectin and its role in the obesity-induced insulin resistance and related complications. Physiol Res 53: 123-129, 2004. 
HAVEL PJ: Control of energy homeostasis and insulin action by adipocyte hormones: leptin, acylation stimulating protein, and adiponectin. Curr Opin Lipidol 13: 51-59, 2002.

HOWARD G, O'LEARY DH, ZACCARO D, HAFFNER S, REWERS M, HAMMAN R, SELBY JV, SAAD MF, SAVAGE P, BERGMAN R: Insulin sensitivity and atherosclerosis. The Insulin Resistance Atherosclerosis Study (IRAS) Investigators. Circulation 93: 1809-1817, 1996.

HUO Y, LEY K: Adhesion molecules and atherogenesis. Acta Physiol Scand 173: 35-43, 2001.

KAWANAMI D, MAEMURA K, TAKEDA N, HARADA T, NOJIRI T, IMAI Y, MANABE I, UTSUNOMIYA K, NAGAI R: Direct reciprocal effects of resistin and adiponectin on vascular endothelial cells: a new insight into adipocytokine-endothelial cell interactions. Biochem Biophys Res Commun 314: 415-419, 2004.

KOMERS R, VRÁNA A: Thiazolidinediones - tools for the research of metabolic syndrome X. Physiol Res 47: 215225, 1998.

KUBOTA N, TERAUCHI Y, YAMAUCHI T, KUBOTA T, MOROI M, MATSUI J, ETO K, YAMASHITA T, KAMON J, SATOH H, YANO W, FROGUEL P, NAGAI R, KIMURA S, KADOWAKI T, NODA T: Disruption of adiponectin causes insulin resistance and neointimal formation. $J$ Biol Chem 277: 25863-25866, 2002.

LEHMANN JM, MOORE LB, SMITH-OLIVER TA, WILKISON WO, WILLSON TM, KLIEWER SA: An antidiabetic thiazolidinedione is a high affinity ligand for peroxisome proliferator-activated receptor gamma (PPAR gamma). J Biol Chem 270: 12953-12956, 1995.

LEHRKE M, REILLY MP, MILLINGTON SC, IQBAL N, RADER DJ, LAZAR MA: An inflammatory cascade leading to hyperresistinemia in humans. PLoS Med 1: e45, 2004.

LIM HS, MACFADYEN RJ, BAKRIS G, LIP GY: The role of hyperglycaemia and the hypercoagulable state in the pathogenesis of cardiovascular events in diabetes mellitus: implications for hypertension management. Curr Pharm Des 12: 1567-1579, 2006.

LOVISCACH M, REHMAN N, CARTER L, MUDALIAR S, MOHADEEN P, CIARALDI TP, VEERKAMP JH, HENRY RR: Distribution of peroxisome proliferator-activated receptors (PPARs) in human skeletal muscle and adipose tissue: relation to insulin action. Diabetologia 43: 304-311, 2000.

MAYERSON AB, HUNDAL RS, DUFOUR S, LEBON V, BEFROY D, CLINE GW, ENOCKSSON S, INZUCCHI SE, SHULMAN GI, PETERSEN KF: The effects of rosiglitazone on insulin sensitivity, lipolysis, and hepatic and skeletal muscle triglyceride content in patients with type 2 diabetes. Diabetes 51: 797-802, 2002.

MCTERNAN CL, MCTERNAN PG, HARTE AL, LEVICK PL, BARNETT AH, KUMAR S: Resistin, central obesity, and type 2 diabetes. Lancet 359: 46-47, 2002.

MOORE KJ, ROSEN ED, FITZGERALD ML, RANDOW F, ANDERSSON LP, ALTSHULER D, MILSTONE DS, MORTENSEN RM, SPIEGELMAN BM, FREEMAN MW: The role of PPAR-gamma in macrophage differentiation and cholesterol uptake. Nat Med 7: 41-47, 2001.

NOLAN JJ, LUDVIK B, BEERDSEN P, JOYCE M, OLEFSKY J: Improvement in glucose tolerance and insulin resistance in obese subjects treated with troglitazone. N Engl J Med 331: 1188-1193, 1994.

OLEFSKY JM: Treatment of insulin resistance with peroxisome proliferator-activated receptor gamma agonists. $J$ Clin Invest 106: 467-472, 2000.

PISCHON T, BAMBERGER CM, KRATZSCH J, ZYRIAX BC, ALGENSTAEDT P, BOEING H, WINDLER E: Association of plasma resistin levels with coronary heart disease in women. Obes Res 13: 1764-1771, 2005.

PLOMGAARD P, KELLER P, KELLER C, PEDERSEN BK: TNF-alpha, but not IL-6, stimulates plasminogen activator inhibitor-1 expression in human subcutaneous adipose tissue. $J$ Appl Physiol 98: 2019-2023, 2005.

RAVUSSIN E, SMITH SR: Increased fat intake, impaired fat oxidation, and failure of fat cell proliferation result in ectopic fat storage, insulin resistance, and type 2 diabetes mellitus. Ann N Y Acad Sci 967: 363-378, 2002.

REAVEN GM: Role of insulin resistance in human disease. Diabetes 37: 1595-1607, 1988.

REAVEN GM: Syndrome X. Blood Press Suppl 4: 13-16, 1992.

REAVEN G: Syndrome X. Curr Treat Options Cardiovasc Med 3: 323-332, 2001.

SALTIEL AR, OLEFSKY JM: Thiazolidinediones in the treatment of insulin resistance and type II diabetes. Diabetes 45: 1661-1669, 1996. 
SAVAGE DB, SEWTER CP, KLENK ES, SEGAL DG, VIDAL-PUIG A, CONSIDINE RV, O'RAHILLY S: Resistin/ Fizz3 expression in relation to obesity and peroxisome proliferator-activated receptor-gamma action in humans. Diabetes 50: 2199-2202, 2001.

SHIMADA K, MIYAZAKI T, DAIDA H: Adiponectin and atherosclerotic disease. Clin Chim Acta 344: 1-12, 2004.

STEPPAN CM, BAILEY ST, BHAT S, BROWN EJ, BANERJEE RR, WRIGHT CM, PATEL HR, AHIMA RS, LAZAR MA: The hormone resistin links obesity to diabetes. Nature 409: 307-312, 2001.

SU CG, WEN X, BAILEY ST, JIANG W, RANGWALA SM, KEILBAUGH SA, FLANIGAN A, MURTHY S, LAZAR MA, WU GD: A novel therapy for colitis utilizing PPAR-gamma ligands to inhibit the epithelial inflammatory response. J Clin Invest 104: 383-389, 1999.

TAN GD, FIELDING BA, CURRIE JM, HUMPHREYS SM, DESAGE M, FRAYN KN, LAVILLE M, VIDAL H, KARPE F: The effects of rosiglitazone on fatty acid and triglyceride metabolism in type 2 diabetes. Diabetologia 48: 83-95, 2005.

TSIOUFIS C, DIMITRIADIS K, CHATZIS D, VASILIADOU C, TOUSOULIS D, PAPADEMETRIOU V, TOUTOUZAS P, STEFANADIS C, KALLIKAZAROS I: Relation of microalbuminuria to adiponectin and augmented C-reactive protein levels in men with essential hypertension. Am J Cardiol 96: 946-951, 2005.

VAMECQ J, LATRUFFE N: Medical significance of peroxisome proliferator-activated receptors. Lancet 354: 141-148, 1999.

\section{Corresponding author}

M. Haluzík, Third Department of Internal Medicine and First Faculty of Medicine, Charles University, U nemocnice 1, 12800 Prague 2, Czech Republic. E-mail: mhalu@lf1.cuni.cz 